\title{
OS COLÉGIOS JESUÍTICOS EUROPEUS E SUAS INFLUÊNCIAS NO TEATRO POPULAR DE JOSÉ DE ANCHIETA: A ARTE DE CONVENCER
}

\author{
LOS COLEGIOS JESÚITICOS EUROPEOS Y SUS INFLUENCIAS EN EL \\ TEATRO POPULAR DE JOSÉ DE ANCHIETA: EL ARTE DE CONVENCER
}

\author{
Camila Nunes Duarte Silveira \\ Faculdades Santo Agostinho (FASA) \\ Vitória da Conquista, Bahia
}

\begin{abstract}
Ana Palmira Bittencourt Santos Casimiro
Universidade Estadual do Sudoeste da Bahia (UESB)

Maria Cleidiana Oliveira de Almeida

Instituto Federal da Bahia (IFBA)
\end{abstract}

\section{Resumo}

A prática teatral não era novidade para os primeiros jesuítas que vieram para o Brasil. Na Europa, desde a fundação da Ordem e dos primeiros colégios, os jesuítas faziam amplo uso dos recursos cênicos como parte constituinte do currículo de seus estudantes. As representações eram recursos para as práticas oratórias como forma de expor os conteúdos aprendidos, sendo também importante artifício das comemorações. Sua obrigatoriedade já se fazia presente nas Constituições da Companhia e perdurou no texto da Ratio Studiorum. No contexto da América Portuguesa, José de Anchieta fez amplo uso de seus conhecimentos em retórica, adquirido no Colégio das Artes, em Coimbra, para criar um teatro adaptado ao seu público, formado principalmente por indígenas. Neste sentido, o presente estudo teve por objetivo analisar tal prática teatral nos Colégios Jesuíticos, especialmente no Colégio das Artes, em Coimbra, com vistas a identificar os elementos que subsidiaram José de Anchieta na criação de um teatro adaptado ao contexto da América Portuguesa. Os resultados apontaram que Anchieta não esqueceu seus estudos no colégio conimbricense, mas, pelo contrário, adaptou-os ao contexto do Novo Mundo, e soube aplicá-los à conjuntura social de acordo com as finalidades de catequização pensadas pelos jesuítas. 
Palavras chave: Teatro. Colégios Jesuíticos. José de Anchieta. América Portuguesa.

\section{Resumen}

La práctica teatral no era una novedad para los primeros jesuitas que vinieron a Brasil. En Europa, desde la fundación de la Orden y de los primeros colegios, los jesuitas hacían un amplio uso de los recursos escénicos como parte constituyente del currículo de sus estudiantes. Las representaciones eran recursos para las prácticas oratorias como forma de exponer los contenidos aprendidos, siendo también importante artificio de las conmemoraciones. Su obligatoriedad ya se hacía presente en las Constituciones de la Compañía y perduró en el texto de la Ratio Studiorum. En el contexto de la América Portuguesa, José de Anchieta hizo un amplio uso de sus conocimientos en la retórica, adquirida en la Facultad de Artes, en Coimbra, para crear un teatro adaptado a su público, compuesto en su mayoría por indígenas. En este sentido, el presente estudio tuvo como objetivo examinar dicha práctica teatral en colegios jesuitas, especialmente en la Facultad de Artes de Coimbra, con el fin de identificar los elementos que apoyaron José de Anchieta en la creación de un teatro adaptado al contexto de América Portuguesa. Los resultados apuntaron que Anchieta no olvidó sus estudios en el colegio conimbricense, pero, por el contrario, los adaptó al contexto del Nuevo Mundo y supo aplicarlos a la coyuntura social de acuerdo con las finalidades de catequización pensadas por los jesuitas.

Palabras clave: Teatro. Colegios Jesuitas. José de Anchieta. América Portuguesa.

\section{A Companhia de Jesus e a organização de seus colégios}

Após ser oficialmente reconhecida como Ordem Religiosa ${ }^{\mathrm{i}}$, em um curto espaço de tempo, essa Ordem, nascida no seio da Modernidade, tomou a direção de importantes trabalhos, que iam desde as missões diplomáticas, orientação teológica no Concílio de Trento (1545-1563), até à administração de colégios. Isso acontecia porque os padres que se somavam à Companhia de Jesus tinham, por ideal, a "maior glória divina" 
Ao organizar a Ordem, a intenção de seu fundador, Inácio de Loyola, não foi a de investir na educação. Seu interesse estava nos ministérios apostólicos mais comuns à época: pregações, confissões, missões, contudo, ele encontrava dificuldade em expandir o número de membros da Companhia. Como não havia adultos suficientes interessados, era preciso receber adolescentes e, para isso, foi necessário prepará-los intelectualmente. Questão essa que levou Inácio e seus companheiros a pensarem na organização dos primeiros colégios ${ }^{\mathrm{ii}}$ (SCHMITZ, 1994; GUTIÉRREZ, 1997).

Embora tenham sido formados inicialmente para suprir às necessidades da Ordem, os jesuítas entenderam, pela experiência, que a educação dos jovens poderia ser ampliada, abrangendo membros externos ${ }^{\mathrm{iii}}$, vez que esses colégios poderiam constituir-se em importantes espaços de evangelização, especialmente nos países não cristãos. A finalidade educacional estava em formar o homem completo, corpo e alma, indissolúveis, unidos em função da vontade de Deus, conforme definiu Loyola nos Exercícios Espirituais. Neste sentido, “[...] visa a educação inaciana a formar homens pessoalmente livres e responsáveis, a serviço de Deus e de seus próximos" (SCHMITZ, 1994, p. 17). Este homem deveria ser autoconsciente e ter responsabilidades sociais. Os colégios da Companhia de Jesus iam se multiplicando por toda a Europa e no Ultramar. Segundo Leonel Franca (1952), em poucos anos, muitos deles se tornaram em grandes centros de cultura humanista.

Os colégios da Companhia de Jesus, segundo as orientações presentes na Ratio Studiorum, eram organizados em cinco classes chamadas de inferiores, sendo elas: retórica, humanidades, e três classes de Gramática. As duas primeiras eram cursadas, em média, num período de dois anos. As de gramática dividiam-se em três partes, uma para cada classe, e em cada uma delas deveria ser repetido o que fora ensinado na classe imediatamente inferior. Por fim, o aluno ascendia ao curso de filosofia, o que deveria ser feito após os estudos da retórica e das humanidades, e tinha a duração de três anos. Ao todo, a formação do aluno nos colégios jesuíticos era realizada em torno de cinco a seis anos, mediante estudos de gramática, retórica e humanidades e três anos de filosofia. Esta última abrangia a lógica, física, metafísica, moral e as matemáticas (HOLANDA, 1972, p. 143). O Real Colégio das Artes de Coimbra, entregue aos cuidados da Companhia de Jesus por D. João III, em 1555, organizou dessa forma os seus estudos, e por esta razão constituiu-se num modelo para os demais colégios jesuíticos a serem organizados, tanto na Europa quanto no Ultramar. 
Camila Nunes Duarte Silveira, Ana Palmira Bittencourt Santos Casimiro, Maria Cleidiana 87 Oliveira de Almeida

Desde a fundação dos seus primeiros colégios, no século XVI, os jesuítas investiram nas representações teatrais como um relevante recurso pedagógico. O teatro jesuítico advém, portanto, das primeiras escolas européias. Segundo Gutiérrez (1997, p. 29), a Companhia de Jesus, desde o seu primeiro momento, fez uso do teatro nas escolas como meio de aperfeiçoar a aprendizagem da língua latina. Além disso, as representações teatrais eram utilizadas como meios de atrair alunos e padres. Gutiérrez afirma que o teatro da Companhia de Jesus foi conhecido em todas as populações importantes da Europa. O’Malley (2004, p. 348) corrobora com Gutiérrez ao afirmar que, embora não tenham inventado o "drama escolar", os jesuítas o utilizaram por um largo período de tempo e numa grande quantidade de colégios.

Afirma João Adolfo Hansen que, no século XVI, os Jesuítas definiam a representação, em geral, como teatro sacro ou encenação de sacralidade da teologia-política a qual recuperava a eloquência dos autores pagãos, bem como dos doutores da Igreja (patrística e escolástica), como um modelo oral para os pregadores contra-reformados. Para o autor: "A escolha da via oral para transmitir a verdade canônica confirmada no Concílio de Trento resultou em extraordinária reativação da Retórica antiga" (HANSEN, 2007, p. 25).

No estudo que faz sobre o teatro no colégio dos Jesuítas, Margarida Miranda afirma que o amplo papel que o teatro desempenhou na história da educação jesuítica começou justamente nos colégios de Espanha e de Portugal, estendendo-se à Itália e, daí, a toda a Europa. A autora destaca, em especial, as dramatizações no Colégio das Artes, em Coimbra, lugar onde José de Anchieta teve a sua formação. Sobre o Colégio, a autora afirma que:

[...] se Coimbra não foi, na verdade, o berço do teatro Jesuítico - pois também já se praticava profusamente nos colégios de Espanha, de Itália e do Norte da Europa -, o Colégio das Artes foi, sem dúvida, o berço da tragédia humanística jesuítica, tal como a Companhia a codificou e promoveu (MIRANDA, 2006, p. 286).

Foi a partir da criação do Colégio das Artes que a produção dramática, bem como a sua representação, foi integrada na Ratio Studiorum como elementos fundamentais para a formação retórica e moral dos alunos. Conforme pontuou Soares (2004, p. 11), "Firma-se, nesta altura, a tradição do teatro escolar que se impõe pela qualidade do texto dramático, pela música dos coros, pela espectacularidade cénica".

\begin{tabular}{l|l} 
Revista RBBA & Revista Binacional Brasil Argentina
\end{tabular} 
Miranda afirma que, ao contrário do que muitos historiadores do teatro pensaram, o que no início parecia ser um exercício escolar, ou experiência dos humanistas eruditos para uma elite de discípulos, tornou-se, afinal, um espetáculo público de grande dimensão social, capaz de responder aos gostos e às preocupações da época. Para a autora, não foi apenas um instrumento de catequese, de inspiração moralizante, mas, o eco das grandes controvérsias do tempo (políticas, morais e religiosas) e, ao mesmo tempo, reflexo natural de costumes de instituições, de uma concepção do mundo, do homem e da ordem humana, expressão das confissões dominantes e controvérsias opostas. Para a autora, se o objetivo do teatro era educar para a eloquência, os mestres-dramaturgos souberam aproveitar o seu valor essencialmente formativo e convertê-lo também em veículo do ensino da doutrina e da moral (MIRANDA, 2006).

No que concerne aos colégios jesuíticos da Europa, é sabido que as aulas e os programas das práticas religiosas os sustentavam, no entanto, desde a sua concepção, as peças de teatro, bem como as celebrações acadêmicas, tinham um importante papel na formação dos escolares, pois lhes possibilitavam exibir seus talentos e habilidades a um público mais amplo. Os padres jesuítas entendiam que esses eventos faziam parte do "exercitium" requerido de estudantes e constituíam uma parte integral de sua educação (O'MALLEY, 2004, p. 344-5).

No caso específico da metrópole portuguesa, o teatro teve seu reconhecido papel pedagógico por meio dos alvarás régios de D. João III, que prescreviam a realização de representações nas Universidades (SOARES, 2004, p. 11). No século XVI, o teatro era utilizado como um recurso pedagógico que permitia refletir o modo de vida de um determinado grupo, sua cultura, bem como as suas preocupações de ordem religiosa, moral e política. Por esta razão, compunham o currículo dos Colégios da Companhia, entre eles, o Real Colégio das Artes, em Coimbra, local onde Manoel da Nóbrega e José de Anchieta foram formados.

\section{Retórica e humanismo}

Pensar o teatro nos colégios jesuíticos importa que levantemos uma breve discussão sobre a retórica ${ }^{\text {iv }}$. Sem a pretensão de analisá-la em seus aspectos mais técnicos, falamos sobre tal arte especialmente por considerarmos a importante influência da retórica na composição do teatro de José de Anchieta na América Portuguesa. Primeiro, por conta da 
Camila Nunes Duarte Silveira, Ana Palmira Bittencourt Santos Casimiro, Maria Cleidiana 89 Oliveira de Almeida

formação humanística, dos seus autos, das influências recebidas no colégio das Artes, em Coimbra, mas também, por ele ser Jesuíta e pelas influências que a Companhia de Jesus teve com o estudo das artes liberais e sua composição para os documentos que nortearam o agir pedagógico da Ordem. Dentre eles, as Constituições ${ }^{v}$ elaboradas por Inácio de Loyola e, posteriormente, a Ratio Studiorum ${ }^{v i}$ que discute mais deliberadamente sobre os estudos de retórica.

Cabe mencionar que Aristóteles e Tomás de Aquino (escolástico afeiçoado ao pensamento aristotélico) forneceram as bases filosóficas e epistemológicas para a construção de um pensamento cristão católico e podemos constatar então, que a Companhia de Jesus sofreu forte influência desses filósofos e teólogos. No que concerne à organização dos estudos, por exemplo, Miranda (2013) afirma que a tradição escolar dos jesuítas foi caracterizada pela associação entre a tradição universitária escolástica de filosofia natural, fundamentada no pensamento aristotélico e na teologia tomista, em seus programas escolares. Além disso, investiam no conhecimento das línguas antigas e na leitura dos clássicos. Embora a autora tenha se referido aos colégios italianos, podemos afirmar que essa característica foi comum a quase todos os colégios jesuíticos. A filosofia aristotélico-tomista fundamentou a organização da Ratio Studiorum, documento que, como sabemos, regulou o fazer pedagógico dos professores inacianos e lhe deu um caráter de universalidade.

As discussões humanísticas se faziam muito presentes entre os letrados do século XVI, representando uma recuperação do homem e a retomada dos valores clássicos e movendo o pensamento e as produções dos teóricos deste tempo. Neste contexto, a retórica tornou-se uma disciplina importante deste movimento. Assim, a arte de persuadir implicava o engajamento da imaginação e das emoções, tanto quanto do Intelecto. Conforme O’Malley (2004, p. 394), “Mantendo a tradição clássica, os humanistas viram o ‘bom estilo’ que a retórica ajudava a cultivar como intrinsecamente sustentador de "bons costumes"”.

Alexandre Júnior (2010. p. 16) define a retórica como "a ciência da expressividade e arte da comunicação persuasiva". Ele a considera um "fenômeno universal aplicável às sociedades em todas as épocas”. Segundo o mencionado autor (2010, p. 18), as definições do termo retórica, ao longo dos séculos, são múltiplas e diversas, contudo, entre as mudanças e continuidades que se apresentam, os objetivos primários da retórica são sempre: “iluminar a

\begin{tabular}{l|l} 
Revista RBBA & Revista Binacional Brasil Argentina
\end{tabular} 
compreensão, agradar à imaginação, tocar nas cordas mais sensíveis da emoção e da paixão, influir na vontade e mobilizar para a acção". O cerne da retórica está em influenciar o outro por meio da linguagem e dos sistemas simbólicos de que dispomos, numa intrínseca relação entre a palavra e a imagem (ALEXANDRE JÚNIOR, 2010, p. 19).Neste sentido, é possível apreender a sua inerente relação com o teatro, cujo objetivo é despertar emoções no público receptor e "define-se como experiência emocional e intelectual, com uma função emotiva, um valor didáctico"(SOARES, 2004, p. 12).

Os preceitos retóricos estão intrinsecamente relacionados ao despertar das emoções que podem ser movidas por meio da boa oratória a qual, por sua vez, precisa ser conhecida. No século XVI, esse conhecimento derivava, em grande parte, dos autores clássicos, recuperados pelos humanistas. Para O’Malley, os jesuítas souberam adaptar bem os conteúdos humanísticos sem, contudo, desprezar a teologia escolástica. Eles souberam aproveitar de vários modos e graus os elementos do fenômeno humanista, e reconheceram nos tratados clássicos, a importância de formarem oradores bem-sucedidos, com capacidade de contatar aos sentimentos e necessidades de seu público, adaptando-se os discursos. "A dimensão retórica do ministério jesuíta transcendia a pregação e as preleções nas quais estavam engajados [...]" (O’MALLEY, 2004, p. 398). Ela envolvia a adaptação ao tempo e lugar e, com isso, o modo de proceder dos inacianos.

Nos colégios jesuíticos do século XVI, a retórica tornou-se umas das principais disciplinas de ensino. Em Portugal, constituiu-se como modelo para todas as práticas de representação, até o final do século XVIII e, no Brasil, ainda se prolongou até a segunda metade do século XIX (HANSEN, 2007).

Apesar dos caminhos distintos aos quais a retórica pode levar, na sua dimensão técnica ou como arte, o que pretendemos destacar, no entanto, é a sua primeira finalidade, a qual, segundo Miranda (2013, p. 196), seria “Agir sobre a vontade, o desejo, o afecto e o intelecto dos ouvintes". Não sem levar em consideração a memoria e actio, as quais, somadas à inuentio, dispositio e elocutio, compõem a retórica. Embora fossem atividades exclusivas dos colégios da Companhia, é sobre esse olhar que conjecturamos os elementos retóricos presentes no teatro de José de Anchieta. Elementos adaptados aos costumes nativos, mas, capazes de mover e agir sobre os afetos e o intelecto de seus ouvintes.

\section{José de Anchieta: o canário de Coimbra nas terras brasílicas}


Camila Nunes Duarte Silveira, Ana Palmira Bittencourt Santos Casimiro, Maria Cleidiana 91 Oliveira de Almeida

Nascido em San Cristóbal de La Laguna, em Tenerife, nas ilhas Canárias, pertencentes à Espanha, no dia 19 de março de 1534, José de Anchieta foi o terceiro dos dez filhos que sua mãe, D. Mencia Diaz de Clavijo y Llarena, teve no segundo matrimônio com o escrivão real Juan de Anchieta. No primeiro casamento ela teve dois filhos (VIOTTI, 1989).

Anchieta cursou as primeiras letras em sua terra natal, La Laguna. No seio dos seus familiares, recebeu boa formação em língua latina e formação religiosa. Em 1548, aos quatorze anos, partiu com seu irmão ${ }^{\text {vii }}$ mais velho, Pedro Nuñez, para Coimbra, onde foi recebido no recém fundado Colégio das Artes ${ }^{\text {viii }}$. Segundo Ramalho (1998), pela boa formação que tiveram, Pedro Nuñez, em grau mais adiantado, foi matriculado diretamente na Faculdade de Cânones, dispensando a sua passagem pelo Colégio das Artes. Sobre a formação de Anchieta, Antonio Franco afirma:

Não tinha elle em sua vida cursado outras escolas mais que as de Rhetorica, \& parte de Philosofia em Coimbra; com tudo na Theologia moral, \& especulativa eram tam versado, \& certo, como se toda a vida versara as Universidades (FRANCO,1719, p. 253) .

No tempo em que esteve em Coimbra, segundo Ramalho (1998), no período mais brilhante daquela escola, Anchieta manteve contato com um considerável número de poetas e humanistas latinos, a exemplo de George Buchanan, professor e dramaturgo escocês e Diogo de Teive, presos em 1550, pelo tribunal da Inquisição, acusados, dentre outras razões, por apresentarem tendências reformistas, além de Inácio de Morais, e o jurista Manuel da Costa, dentre outros. Destes, ao menos Diogo de Teive ${ }^{\mathrm{x}}$, reconhecido professor de retórica e excelente dramaturgo, foi professor de Anchieta, o que indica que este teve uma formação humanista aprofundada (RAMALHO, 1998). Segundo Miranda (2000), não podemos dissociar a presença de Anchieta em Coimbra da ação pedagógica que aqueles ilustres mestres desenvolviam no novo Colégio. Assim, presume-se que Anchieta esteve envolvido e pôde participar ativamente da produção do conhecimento que se organizava no chamado "Renascimento".

No Colégio das Artes, Anchieta obteve destaque como um dos melhores alunos. Teve contato com teatro de tema religioso, e conheceu as peças bíblicas produzidas por seu 
principal mestre, Diogo de Teive. Viotti (1966) e Ramalho (1998). Afirmam que Anchieta ficou conhecido entre os colegas como "canário de Coimbra", uma alusão feita à ave e à sua terra de origem. Ramalho (1998) se questiona como foi possível, entre os 1.500 alunos, Anchieta ter tido essa reputação. Ele encontra razão no fato de, possivelmente, o título ter sido obtido por uma vitória num concurso, uma vez que as competições entre os escolares eram frequentes e, como um bom latinista, Anchieta distinguia-se dos demais colegas (RAMALHO, 1998).

Ainda em Coimbra, Anchieta conheceu a nova Ordem fundada por Inácio de Loyola e em 1551 decidiu ser um dos missionários da Companhia de Jesus. A 08 de maio de 1553, em virtude de uma doença ${ }^{\mathrm{xi}}$ de que fora acometido, antes de finalizar o seu curso de Artes, embarcou de Lisboa com destino à América Portuguesa a fim de recuperar-se nas novas terras que tinham por fama de ambiente saudável.

Anchieta embarcou na terceira expedição jesuítica em companhia do superior da Ordem e chefe da expedição, Pe. Luis da Grã, e dois sacerdotes, Brás Lourenço e Ambrósio Pires. Além destes, também foram enviados os irmãos estudantes ${ }^{x i i}$ João Gonçalves, Antônio Blásquez e Gregório Serrão. Segundo Viotti (1966), todos eles possuíam algum tipo de enfermidade, o que nos conduz a afirmar que, além do desejo missionário, certamente almejavam tratar as suas doenças. Esses homens compunham a frota ${ }^{\text {xii }}$ do segundo Governador Geral do Brasil, Dom Duarte da Costa e, nas novas terras, auxiliariam Manoel da Nóbrega e seus companheiros no trabalho missionário e, por conseguinte, no projeto colonial.

Os jesuítas aportaram nas novas terras em 13 de julho de 1553, e em pouco tempo Anchieta já confessava a melhora da saúde. O noviço compartilhou as boas novas com seus irmãos enfermos de Coimbra. Na carta de 1554 ele diz:

\footnotetext{
Por outras cartas vos tenho já escrito de minha disposição, a qual cada dia se renova, de maneira que nenhuma diferença há de mim a um são [...] sei dizer que se o Padre Mirão quiser mandar-vos a todos os que andais opilados e meio doentes, a terra é mui bôa e ficareis mui sãos (ANCHIETA, 1988, p. 73-74). ${ }^{\text {xiv }}$
}

Logo nos primeiros dias, os missionários iniciaram as suas atividades. Anchieta, sempre que pôde, esteve ao lado de Nóbrega, então nomeado Provincial da Companhia de Jesus. Acerca do seu trabalho, escreveu Simão de Vasconcelos: 
Aqui deu principio Ioseph ao fervor de seus grandes intentos. Começou logo elle, \& os companheiros a por a caza em forma de Collegio, pregando, ainda os que nam eram Sacerdotes, abrindo classes de ler, escrever, grammatica, \& fazendo os mais ministérios da Compahia, com mesma perfeiçam de muitos, sendo de dez sómente o numero das que estavam, \& chegaram de novo (VASCONCELOS, 1672, p. 18).

Anchieta não somente exerceu o trabalho educativo, por assumir com o seu Provincial a liderança do primeiro colégio dos jesuítas na América Portuguesa, estabelecido em Piratininga, no ano de 1554, o chamado "Colégio de São Paulo"xv , como também atuou politicamente, intermediando conflitos entre os próprios indígenas, entre indígenas e colonizadores e por pugnar, ao lado de Mem de Sá, contra invasores, a exemplo da luta contra os franceses. Sendo que, em 1563, no Armistício de Iperoig, se ofereceu como refém dos Tamoios em prol da pacificação entre os indígenas e portugueses, e derrota dos franceses.

Tratou rapidamente de aprender a língua nativa e, antes de 1556, já tinha redigido a “Gramática da língua mais usada na costa do Brasil”, tornada obrigatória em 1560, por Luis da Grã. Essa gramática foi um instrumento facilitador da aprendizagem da língua nativa para os missionários que chegavam à Colônia. Na mesma carta enviada aos seus irmãos de Coimbra, Anchieta apresenta seu trabalho inicial:

Quanto à língua eu estou adiantado, ainda que é mui pouco, pera o que soubera se me não ocupara em ler gramatica; todavia tenho coligido toda a maneira de dela por arte, e pera mim tenho entendido quase todo seu modo [...] só eu me aproveito dela e aproveitar-se-ão os que de lá vierem e souberem gramatica (ANCHIETA, 1988, p. 74). ${ }^{\text {xi }}$

Outras produções foram criadas para o bom andamento do trabalho. Escreveu os Diálogos da Fé, texto no qual organizou a maior parte da Doutrina Cristã, composto em língua tupi e, ainda, alguns catecismos, "Instrução para o batismo", "Instrução para assistência aos Índios em perigo de morte", e um “Confessionário". Também em tupi — além de outras línguas, como o castelhano, latim e português - compôs canções e autos sacros com o fim de evangelizar e divertir indígenas escravizados, ou forros, das aldeias cristãs (VIOTTI, 1966). Todas as produções eram divulgadas entre os padres e amplamente utilizadas na educação dos indígenas. Além dos trabalhos diretamente dirigidos à doutrina e 
catequese, Anchieta ainda compôs poemas, a exemplo do louvor à virgem "De Beata Virgine Dei Matre Maria”xvii, e uma epopeia, "De Gestis Mendi de Saa”, ambos escritos em 1563. Sobre os seus escritos, escreveu Afranio Peixoto:

Não importa a versão; taes versos e autos tupís, no original, exerceram sua utilidade, de edificação. Rezas e mistérios na língua dos Indigenas, como orações, catecismo, letras, foram a taboada em que começou a soletrar a civilização (PEIXOTO, 1988, p. 34).

Embora não mencione quais, o Padre Antonio Franco afirma que Anchieta ainda fez tradução de cantigas profanas que se propagavam em Portugal. Embora as tenha traduzido, o interesse era dar-lhes ares de santidade, certamente com adaptações cristãs.

Como era mui destro nas quatro lingoas Portugueza, Castelhana, Latina, e Brasilica, traduzio em todas ellas em romances pios, \& mui engraçados as cantigas profanas que andavam em uso. Donde se seguio fazer esquecidas as profanas, ouvindose cantar pellos caminhos, as que elle tinha posto em suave, \& santo metro (FRANCO, 1719, p.233).

Tais adaptações foram consideradas por Cardoso (1997) como um traço original de Anchieta. Para o mencionado autor, as canções populares adaptadas constituíram um importante recurso apostólico de moralidade pública e "elevação da cultura". Anchieta escolhia, principalmente, aquelas que lhes pareciam mais atraentes pela música, e que mais facilmente cairiam no gosto popular, com melodias já conhecidas pelos indígenas e colonos.

Anchieta tornou-se o quinto provincial do Brasil no ano de 1578 e ocupou o cargo, na Bahia, por pouco mais de dez anos. No tempo em que esteve à frente do trabalho missionário, visitou continuamente as províncias, os engenhos e os aldeamentos, participando, inclusive, de expedições com vistas a promover os descimentos. Segundo Viotti, durante o seu provincialado fundou no Espírito Santo as aldeias de Reritiba, de Guarapari e dos Reis Magos. No Rio de Janeiro fundou a aldeia de São Barnabé no Rio Macacu e, em São Paulo, participou da fundação das aldeias de Marueri e de Guarulhos (VIOTTI, 1966).

Ao ser substituído por Marçal Beliarte, em 1587, Anchieta mudou-se para o Espírito Santo, e lá assumiu o cargo de superior da Residência de São Tiago, bem como das aldeias subordinadas a ela. Foi nesta capitania que produziu a maioria de suas obras literárias para instrução dos indígenas. Conforme o mencionado autor, por mais tempo que lhe custassem as 
Camila Nunes Duarte Silveira, Ana Palmira Bittencourt Santos Casimiro, Maria Cleidiana 95 Oliveira de Almeida

contínuas viagens e, por vezes, o tempo em que ficara acamado recuperando-se das suas enfermidades, em momento algum, o padre renunciara às suas atividades literárias (VIOTTI, 1966).

Entre os missionários das novas terras, Anchieta apresentava qualidades singulares. Era exímio orador, tinha uma memória privilegiada e sabia adaptar-se ao seu auditório, atingindo o coração dos ouvintes. Qualidades certamente adquiridas pelos estudos e exercícios constantes no Colégio das Artes.

A sua formação clássica e humanista ofereceu subsídios para atuar frente à realidade com que se deparou nas novas terras brasílicas, realidade que exigiu dele certa originalidade em suas produções literárias. As peças por ele produzidas durante o seu apostolado nas novas terras não poderiam ser latinas, visto que o seu público, tanto indígena, quanto colonizadores era, em sua maioria, inculto. Por isso, a fim de obter maior alcance em sua atividade missionária, optou por apresentar em seus escritos um estilo popular "uma espécie de Gil Vicente simplificado, e em tupi, castelhano e português" (RAMALHO, 1997, p. 222). Cabe mencionar que, das influências sofridas por Anchieta no seu tempo de estudante no Colégio das Artes, destacam-se principalmente, as obras de Gil Vicente. Muitas das suas ideias e expressões estão presentes na obra anchietana, tanto nos autos, quanto nas poesias e sermões.

\section{Primórdios do teatro na América Portuguesa}

Reconhecida a sua importância, não somente como recurso educacional, mas como meio de distrair e alegrar o público, os documentos atestam a prática teatral na América Portuguesa, antes mesmo da chegada dos missionários jesuítas ${ }^{\mathrm{xviii}}$. $\mathrm{O}$ teatro fora trazido nas naus portuguesas vez que, como é possível observar na obra de Carlos Francisco Moura, no século XVI, tripulações e passageiros representavam a bordo comemorações religiosas e divertimentos tradicionais, comuns em Portugal (MOURA, 2000). Podemos deduzir, por esses registros, que o teatro não foi trazido para América Portuguesa pelos jesuítas, entretanto, foi por meio de José de Anchieta que as representações teatrais se tornaram importantes ferramentas de doutrinação e catequese da sociedade colonial. 
Os autos "poucos decentes" estavam presentes no contexto colonial e eram representados até nas igrejas com o especial objetivo de distrair o público. O teatro de Anchieta, iniciado por meio de uma encomenda feita pelo padre Manoel da Nóbrega, motivou a representação da primeira peça de cunho religioso substituindo as peças leigas, com o objetivo de moralizar e doutrinar os indígenas e colonos. Foi o próprio Anchieta quem escreveu sobre a razão do auto:

E por impedir alguns abusos que se faziam em autos nas igrejas, fez um ano com os principais da terra que deixassem de representar um que tinham, e mandou-lhes fazer outro, por um Irmão, a que ele chamava Pregação Universal [...]. E a gente movida com muita devoção ganhou o jubileu, que era o principal intento da obra (ANCHIETA, 1984, p. 18).

A respeito do assunto, temos notícias também do Padre Simão de Vasconcelos, que escreveu:

\begin{abstract}
De hũa das comedias he força fazer aqui menção. Em S. Vicẽnte afim de impedir as indecẽncias que se cometião em actos representados na Igreja, introdusio co aplauso dos moradores da Villa, \& parecer do Padre Nobrega seu superior, hum acto seu, muito devoto, a que chamava Pregaçam universal, porque servia pera todos, Portugueses, \& Indios; \& constava de huma, $\&$ outra lingoa, porque de todo fosse entendido: A este concorria a gente toda; representatavase na vesporas de Iubileo da festa de Iesu, porque tambem a volta do acto fosse universal o ganho de suas indulgencias (VASCONCELOS, 1672, p. 26).
\end{abstract}

No primeiro século da colonização, as representações teatrais apresentavam características muito peculiares. As condições sociais e materiais da colônia não comportavam, sem dúvida, as tragédias clássicas representadas nos colégios europeus. Segundo Cardoso (1977, p. 57), "Nosso teatro, tanto de aldeias indígenas como de vilas de colonos, em todo o século XVI, conservava-se profundamente popular, como Anchieta o criou". Em uma sociedade marcada pela oralidade, o teatro vinha a ser um inexorável elemento pedagógico, o qual, longe de ser estruturado segundo as rigorosas regras dos colégios europeus, foi moldado ao contexto ameríndio, compondo um novo veículo cênico.

A linguagem verbal e visual persuadia com grande força, vez que os jesuítas não mediam esforços em compor um cenário teatral rico em música, cantos, enfeites, belos vestuários e primorosa eloquência. A finalidade deste teatro era alcançar o indígena, mas, 
Camila Nunes Duarte Silveira, Ana Palmira Bittencourt Santos Casimiro, Maria Cleidiana 97 Oliveira de Almeida

também, outros moradores das novas terras, colonos, degredados, soldados e pequenos comerciantes. Por esta razão, as composições eram revestidas de um caráter popular, compatível com a capacidade de compreensão do público ao qual se destinava.

Tinham a finalidade de representar os dramas bíblicos, vinculando-os às práticas culturais nativas em que as imagens de Jesus, Maria, anjos, demônios e demais personagens presentes no cristianismo eram assimilados, sempre que possível, aos heróis dos mitos tupis, como forma de aproximação ou de, sobretudo, demonizar os costumes a hábitos indígenas. Segundo Clarice Cortez, “o objetivo era incutir a concepção cristã do Universo, despertandolhes a consciência para a percepção do eterno conflito entre o bem e o mal, simbolizados em Deus e no Diabo [...]" (CORTEZ, 2000, p. 347).

Este conflito foi amplamente explorado no contexto cristão do Velho Mundo devido às elaborações sobre a demonologia e nitidamente expresso nos conceitos de bem e mal. A América Portuguesa constituía o espaço ocupado pela presença do Diabo e de seus ajudantes, os demônios. Era preciso apresentá-los aos nativos.

Neste sentido, não podemos deixar de considerar que o teatro de José de Anchieta, como arte dramática ou catecismo é, segundo Hernandes (2008, p. 11), "um acontecimento histórico", ao ser compreendido como representação pedagógica, como aula de catequese, o mesmo possui enredo, argumento e conteúdo próprio para atender a um público específico. $\mathrm{O}$ teatro anchietano é uma representação cênica situada no tempo a qual, para aproximar-se dele, faz-se necessário "considerá-lo na ordem dos acontecimentos e dos efeitos" (HERNANDES, 2008, p. 11). Cabe ainda dizer que, de modo algum, José de Anchieta manifestou-se contra a sociedade colonial, o seu alvo denunciatório foi a cultura indígena. Nela, os diabos se travestiam da cultura tupi, enquanto os anjos e santos representavam a cultura do colonizador (SUESS, 1997).

O conteúdo do teatro criado por José de Anchieta tinha como principal objetivo explorar os diversos traços da cultura ameríndia os quais foram, propositadamente, associados à idolatria e à demonização. Por meio dos elementos retóricos, tão bem apreendidos nos colégios europeus, e dos recursos imagéticos utilizados, os discursos buscavam convencer os ouvintes de que eles eram pecadores e tentavam modificar as suas ações. Representados, em sua maioria, na língua tupi e portuguesa, os autos protagonizados principalmente pelos 
indígenas convenciam-lhes de algo até então desconhecido por eles, a ideia de pecado "materializada" em seus "maus costumes" e a necessidade de salvar as suas almas.

Ornamentadas de aparatos que tentavam conquistar o público, as representações teatrais objetivavam alcançar a imaginação, para então, alcançar a razão dos presentes. A imaginação, contudo, deveria ser alcançada por meio dos estímulos aos sentidos, especialmente do visível e do audível. Sensibilidades que conduziriam as pessoas à consciência da morte e do pecado. Por meio do terror e do pavor do inferno que lhes inculcavam, os ouvintes eram levados ao convencimento da fé cristã.

O teatro, amplamente trabalhado nos colégios jesuíticos europeus, no século XVI, chegou às terras brasílicas com características distintas das originais, em sua forma e conteúdo. Entretanto, apresentava um objetivo comum: o convencimento e a moção dos afetos da alma, a qual, no contexto da América Portuguesa era principalmente, indígena e carecia de salvação. Esses espetáculos, apesar da distância no tempo, afirmam Hessel e Raedrs, eram "dirigidos para a imaginação e a sensibilidade, simultaneamente vivas e simples nos indígenas, verdadeiras crianças, crianças por vezes perversas, infelizmente” (HESSEL; RAEDRS, 1972, p. 15).

\section{Considerações finais}

No Colégio das Artes, Anchieta obteve uma formação humanista e dela fez uso para organizar as suas representações na América Portuguesa. Os conhecimentos em retórica, principalmente, propiciaram a elaboração de textos cujos conteúdos despertavam em seu público sentimos diversos, dentre eles, o pavor do inferno e a comoção por se reconhecerem pecadores. Claro também está, que as obras anchietanas tinham por objetivo apresentar o anúncio católico, sob a égide da conquista e, para isso, os jesuítas mostram-se bem modernos.

A motivação dos padres jesuítas estava em formar o "homem civilizado" por meio da propagação da fé católica, para tanto, investiram em diferentes estratégias educativas cujo objetivo era transmitir os valores cristãos e apresentar uma "nova forma de vida" aos povos colonizados. Estimularam o ensino das letras, os cânticos e os catecismos. Além disso, promoveram nos aldeamentos e nas escolas a educação moral por meio das representações teatrais, sendo que essas últimas, ganharam especialmente o gosto dos nativos. 
Por meio das representações teatrais, as cenas sacras eram apresentadas ao mundo real dos nativos e colonos de forma a tornarem-se como que realidades vivas. O mundo cristão apresentava-se por meio de palavras e imagens e, uma vez compreendido e aceito, tornava-se o preceito que salvaria o povo do pecado. O teatro era a forma eficiente para que esses elementos fossem agrupados, sobretudo, ao cotidiano ameríndio. Essa correlação foi compreendida e utilizada pelos jesuítas e, especialmente, por José de Anchieta que usou tais recursos à exaustão.

Anchieta chegou às terras brasílicas com formação em Letras e Artes. Durante a sua formação, pôde conviver com a produção do conhecimento humanístico e cristão e dele soube tirar proveito nas novas terras. Possuía conhecimento da retórica e, embora não tenha elaborado nenhum estudo sobre, é possível notá-la em seus autos, estrategicamente criados com a preocupação em persuadir o público, transmitindo os conhecimentos de Deus e da natureza por meio de uma linguagem mais próxima dos ouvintes. Tanto a linguagem falada, como a linguagem gesticulada e corporal, utilizadas nas encenações, foram pensadas para alcançar o gosto popular.

Mais uma vez, apresentamos indícios de que o projeto de colonização do Império Português tinha como escopo a expansão portuguesa. Essa era também uma das intenções da Igreja. No sentido contrário, a Igreja e, maiormente, a Companhia de Jesus, ao tempo em que buscava sinceramente a salvação das "almas" indígenas, buscavam também extirpar os costumes considerados imorais, aos olhos do europeu. Essas eram também as intenções do Estado Português, principalmente visando a submissão dos nativos.

\section{Referências}

ANCHIETA, José de. Cartas: correspondência ativa e passiva. Pesquisa, introdução e notas Pe. Hélio Abranches Viotti. São Paulo: Loyola, 1984.

Cartas Jesuíticas III. Informações, fragmentos históricos e sermões. Belo Horizonte: Itatiaia; São Paulo: Ed. da universidade de São Paulo, 1988.

ALEXANDRE JÚNIOR, Manuel. O poder da retórica na palavra e na acção. In: PEREIRA, Belmiro Fernandes; VÁRZEAS, Marta (Org.). Retórica e teatro: a palavra em acção. 1. ed. Porto, 2010. 
CASIMIRO, Ana Palmira B. S. Elementos fundamentais da pedagogia jesuítica. Educação em Questão, v. 20, n. 6, p. 107-129, maio/ago. 2004.

CORTEZ, Clarice Zamonaro. A ideologia missionária de Anchieta: uma questão a ser discutida. In: PINHO, Sebastião Tavares de; FERREIRA, Luísa de Nazaré (Coord.). Anchieta em Coimbra. Coimbra: Fundação Engenheiro António de Almeida, 2000. v. I-III. p. 341-349.

FRANCA SJ., Leonel. O método pedagógico dos jesuítas: o "Ratio Studiorum". Rio de Janeiro: Livraria Agir, 1952.

FRANCO, Antonio. S. J. Imagem da Virtude em o noviciado da Companhia de Jesus do real Collégio de Coimbra. 1719. Parte Segunda. Livro Segundo.

GUTIÉRREZ, Cayo González. El teatro escolar de los jesuitas (1555-1640). Oviedo: Universidade de Oviedo, 1997.

HANSEN, João Adolfo. A civilização pela palavra. In: LOPES, Heliane Marta Teixiera; FARIA FILHO, Luciano Mendes; VEIGA, Cyntia Greive (Org.). 500 anos de educação no Brasil. 3. ed. Belo Horizonte: Autêntica, 2007.

HERNANDES, Paulo Romualdo. O teatro de José de Anchieta: arte e pedagogia no Brasil Colônia. Campinas, SP: Alínea, 2008.

HESSEL, Lothar; RAEDRS, Georges. O teatro jesuítico no Brasil. Porto Alegre: Universidade Federal do Rio Grande do Sul, 1972.

HOLANDA, Sérgio Buarque de. História geral da civilização brasileira. 4. ed. São Paulo: Difel, 1972. v.1.

LEITE, Serafim. História da companhia de Jesus no Brasil: século XVI. Lisboa: Portucália, 1938. $10 \mathrm{v}$.

MIRANDA, Maria Margarida Lopes de. Teatro jesuítico e teatro de Anchieta: nas origens. In: PINHO, Sebastião Tavares de; FERREIRA, Luísa de Nazaré (Coord.). Anchieta em Coimbra. Coimbra, Fundação Engenheiro António de Almeida, 2000. v. I-III. p. 951-962.

Teatro no colégio dos Jesuítas: a tragédia de Miguel Venegas S.I. e o início de um gênero dramático (sec. XVI). Lisboa: Fundação Calouste Gulbenkian, 2006.

Quando os jesuítas eram mestres da palavra: a retórica segundo a Ratio Stvdiorvm. Humanitas, v. 65, p. 187-203, 2013.

MOURA, Carlos Francisco. Teatro a bordo das naus portuguesas nos séculos XV, XVI, XVII e XVIII. Rio de Janeiro: Instituto Luso-Brasileiro de História. Liceu Literário Português, 2000. 
Camila Nunes Duarte Silveira, Ana Palmira Bittencourt Santos Casimiro, Maria Cleidiana 101 Oliveira de Almeida

O’MALLEY, John W. Os primeiros Jesuítas. São Leopoldo, RS: Ed. UNISINOS; Bauru, SP: EDUSC, 2004.

PEIXOTO, Afranio. Introdução. In: ANCHIETA, José de. Cartas Jesuíticas III: CartasInformações, fragmentos históricos e sermões. Belo Horizonte: Itatiaia; São Paulo: Ed. da Universidade de São Paulo, 1988.

RAMALHO, Américo da Costa. José de Anchieta em Coimbra. HVMANITAS, v. XLIX, p. 215-225, 1997.

A formação conimbricense de Anchieta. HVMANITAS, v. L, p. 709-720, 1998.

SHIMITZ, Egídio. Os jesuítas e a educação: a filosofia educacional da companhia de Jesus. São Leopoldo: Ed. UNISINOS, 1994.

SOARES, Nair de Nazaré Castro. Prefácio. In: MELO, António Maria Martins. Teatro Jesuítico em Portugal no século XVI: a tragicomédia IOSEPHVS do Pe. Luis da Cruz, S.J. Lisboa: Fundação Calouste Gulbenkian - Fundação para a Ciência e a Tecnologia, 2004.

SUESS, Paulo. José de Anchieta e a Memória dos outros. Revista Eclesiástica Brasileira, n. 227, set. 1997.

THOMAS, Joseph S.J. O segredo dos Jesuítas: os exercícios espirituais. São Paulo: Loyola, 1990.

VASCONCELOS, Simão de. Vida do veneravel padre Joseph de Anchieta da companhia de jesu, taumaturgo do nouo mundo, na provincia do Brasil. Composta pello p. Simam de Vasconcellos, da mesma companhia, lente de prima na sagrada theologia, \& prouincial que foi na mesma proiuncia, natural da cidade do Porto. Lisboa: Officina de Ioam da Costa, 1672. Biblioteca Nacional de Portugal- BNP, Lisboa. Documento impresso, acervo de obras raras.

VIOTTI, Hélio Abranches. Anchieta, o apóstolo do Brasil. São Paulo: Loyola, 1966.

Padre José de Anchieta: textos históricos. São Paulo: Loyola, 1989. 9. v. (Obras Completas).

\section{Notas}

${ }^{i}$ Aprovada pelo Papa Paulo III em 27 de Setembro de 1540 por meio da Regimini Militantis Ecclesiae (CASIMIRO, 2004).

ii Os colégios eram espécies de internatos vinculados às universidades mais conhecidas. A partir de 1540 foram criados colégios em Paris (1540), Coimbra (1542), Pádua (1542), Lovaina (1542) Colônia (1544), Valença (1544) e outros (SHIMITZ, 1994). As suas normas dedicavam, principalmente, à catequese das crianças: 
"Ensinar às crianças e à gente simples (os rudes) os demais fundamentos da nossa santa fé católica" (THOMAS, 1990, p.06).

iii $\mathrm{O}$ primeiro colégio para externos (meninos pobres e rudes) foi fundado em Goa, no ano de 1543, por S. Francisco Xavier. Porém, somente em 1548, a pedido do Vice-Rei e da população citadina de Messina, Loyola abriu o primeiro colégio clássico da Companhia de Jesus (FRANCA, 1952).

iv Para os Jesuítas a retórica constituía um acúmulo de saberes, um programa de estudos interdisciplinar que aliava as letras e a virtude, o afeto e intelecto, fé e razão. Na Ratio Studiorum a retórica não é encarada como 'técnica', nem como 'disciplina', mas antes como integração dos saberes, alheia as barreiras tradicionais entre disciplinas. E uma retórica consciente dos laços entre eloquência e vida política, ou entre eloquência e vida cívica ativa (MIRANDA, 2013).

v"Nas constituições feitas entre 1548 e 1550 para os Colégios da Companhia de Jesus, o Pe. João Polanco, [...] determinou que aos domingos fossem sustentadas concussões públicas de Retórica e Poética[...]. Nos colégios Jesuíticos, a Retórica ocupava quatro horas por dia, duas pela manhã e duas à tarde" (HANSEN, 2007, p. 26).

viSegundo Hansen (2007), na Ratio Studiorum, a Retórica deve contar com três elementos essenciais, os quais normalizam e resumem toda a educação: os "preceitos", o "estilo", e a "erudição". Para ensinar essas três coisas em seus colégios os jesuítas deveriam recuperar autoridades antigas, a exemplo de De oratore de Cícero, a Retórica para Herênio, de autor anônimo (atribuída a Cícero) e a Instituição oratória, de Quintiliano. Essas obras forneceriam as regras ou preceitos da eloquência.

vii Pedro Nuñez era o mais velho por parte de mãe (VIOTTI, 1989).

viii Fundado por D. João III, o Colégio das Artes, anexo à Universidade de Coimbra, iniciou as suas atividades em 21 de fevereiro de 1548. Segundo Américo da Costa Ramalho, embora não haja registros da frequência de Anchieta na Universidade, as informações existentes sobre as Artes em Santa Cruz e sobre o Colégio das Artes, possibilitam-nos fazer uma ideia aproximada de seus estudos em Coimbra. De acordo com o referido autor, podemos inferir que José de Anchieta tenha sido aluno do Colégio das Artes por meio dos seguintes fatos: "Pelo Processo Apostólico de Lisboa. Arquivo Secreto Vaticano (ASV), Congr. Rit. ANCHIETA, no 307, $2^{\mathrm{a}} \mathrm{p}$. depoimento do padre Álvaro de Pires, S.J., foi Anchieta colega de aula de D. Jorge de Ataíde. Diogo de Teive no processo inquisitorial, a que foi submetido em 1550, arrola como testemunha de sua ortodoxia esse seu aluno." [Esta informação é tirada do livro Anchieta, o Apóstolo do Brasil, do padre Hélio Abranches Viotti, S. J., que para o processo de Diogo de Teive cita Mário Brandão, A inquisição e os professores do Colégio das Artes, vol. I, Coimbra, 1948, p. 672-673] (RAMALHO, 1998; VIOTTI, 1966).

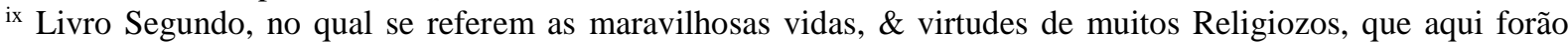
Noviços, e fundarão a Santa província do Brasil, 1719. (manuscrito microfilmado) Biblioteca Nacional de Portugal (BNP).

${ }^{x}$ Diogo de Teive foi professor de Anchieta nos anos de 1548 a 1550. Suas peças tinham como principais conteúdos os temas bíblicos, a exemplo de Golias (CARDOSO, 1997; HERNANDES, 2008).

xi Anchieta precisou interromper seus estudos por ter desenvolvido uma deformidade na espinha dorsal. Segundo Viotti, a doença fora adquirida por consequência dos grandes esforços que fazia, ajudando nas missas, às vezes, dez por dia, jejuando e orando por longos períodos. O autor complementa, mediante estudos feitos nos escritos de um de seus biógrafos, Sebastião Bretário, que o problema fora agravado por uma tuberculose ósteo-articular, localizada na coluna vertebral. Entretanto, Viotti (1996) e Cardoso (1997) afirmaram que sobre este segundo problema não há unanimidade entre os autores.

xii No tempo em que veio para o Brasil, Anchieta ainda não tinha sido ordenado padre, era ainda um noviço chamado pelos companheiros de irmão. Sua ordenação ao sacerdócio ocorreu nas terras brasílicas, em 1566. Ascendeu ao grau de professo, pronunciando os seus votos definitivos, em 1577 (VIOTTI, 1989). Como exigência para a sua ordenação sacerdotal, Anchieta complementou seus estudos (humanísticos, teológicos e filosóficos) na América Portuguesa.

xiii A frota foi composta por uma nau e três caravelas. Levava cerca de 260 pessoas, dentre elas, a terceira leva de Jesuítas, os seis mencionados no texto (VIOTTI, 1989).

xiv Aos Irmãos Enfermos de Coimbra, de São Vicente, 1554.

${ }^{x v}$ Neste colégio Anchieta ensinou o latim, ou seja, as humanidades, a estudantes da Companhia e alunos de fora até o ano de 1563. Também ensinou catecismo e primeiras letras às crianças indígenas (VIOTTI, 1966). Cabe lembrar, que no primeiro momento, os colégios foram criados com o principal objetivo de formar missionários para atuarem nas missões.

xviAos Irmãos Enfermos de Coimbra, de São Vicente, 1554.

xvii Este poema fora escrito no tempo em que Anchieta esteve refém entre os Tamoios, como voto de consagração à virgem. Conta Simão de Vasconcelos que Anchieta escrevera o poema na areia da praia. Enquanto fazia os 
versos, ia decorando-os a fim de transcrevê-los para o papel no momento oportuno. "O feitio mnemonico dos metros facilitava a passagem" (ABREU, 1988, p. 25).

xviii Leite (1938) afirma que o teatro foi introduzido no Brasil pelos colonos. Estes representavam nas igrejas alguns autos à moda portuguesa, organizados ali mesmo, ou mais provavelmente, vindos de Portugal.

\section{Sobre as autoras}

Camila N. D. Silveira. Doutora em Memória: Linguagem a Sociedade pelo Programa de Pós-Graduação em Memória: Linguagem e Sociedade (PPMLS-UESB), na linha de Memória, Cultura e Educação. Mestre em Memória: Linguagem e Sociedade pelo mesmo Programa. Membro do Grupo de Pesquisa Fundamentos da Educação: Memória, Imagem, Religião (Museu Pedagógico-UESB). Atua na Coordenação de Ensino, Pesquisa e Extensão das Faculdades Santo Agostinho em Vitória da Conquista. Endereço Eletrônico: milaped@hotmail.com

Ana Palmira B. S. Casimiro. Professora Plena da Universidade Estadual do Sudoeste da Bahia (UESB) e Professora do Programa de Pós-Graduação em Memória, Linguagem e Sociedade (PPGMLS-UESB). Doutora em Educação pela UFBA e Pós-Doutora em Educação pela UNICAMP. É pesquisadora vinculada ao Grupo de Estudos e Pesquisas História, Educação e Sociedade no Brasil HISTEDBR e ao Museu Pedagógico, no qual coordena o Grupo Fundamentos da Educação: Memória, Imagem, Religião. É autora de publicações na área de História da Arte e História da Educação, com ênfase em barroco e Brasil Colonial. Endereço Eletrônico: anapalmira32@gmail.com

Maria Cleidiana O. de Almeida. Professora do Instituto Federal da Bahia - IFBA. Doutoranda em Memória: Linguagem e Sociedade pelo Programa de Pós-Graduação em Memória: Linguagem a Sociedade (PPMLS-UESB), na linha de Memória, Cultura e Educação. Mestre em Memória: Linguagem e Sociedade pelo mesmo Programa. Membro do Grupo de Pesquisa Fundamentos da Educação: Memória, Imagem, Religião (Museu Pedagógico-UESB). Tem experiência no ensino de História na Educação Básica e no Ensino Superior. Endereço Eletrônico: cleidinha.prof@yahoo.com.br 